\title{
VISTAS E PAISAGENS: IMAGENS DO RIO DE JANEIRO COLONIAL
}

\author{
Ronald Raminelli \\ Universidade Federal Fluminense
}

\section{Resumo}

Ensaio sobre vistas e paisagens do Rio de Janeiro entre os séculos XVII e XIX. Na longa duração torna-se possível perceber como as representações da cidade se modificaram. Inicialmente, as vistas serviam como temas cartográficos, depois os pintores incluíram a civitas na paisagem, destacando, sobretudo, o cotidiano escravista.

\section{Abstract}

Essay on Rio de Janeiro's views and landscapes, between XVII and XIX centuries. In this long period, it is possible to notice an important change in the city representation. At first, the views acted as cartography themes. In the end of eighteenth century, the painter included the civitas in the landscapes.

\section{Pallavras-Chave}

Paisagem Colonial • Viajantes • Rio de Janeiro • Representação

\section{Keywords}

Colonial Landscape $\bullet$ Voyagers $\bullet$ Rio de Janeiro $\bullet$ Representation 
Vista de bordo pela manhã, a cidade apresentava um aspecto imponente por sua posição e por suas numerosas casas e igrejas caiadas de branco: mas, olhadas de perto, desvanecia-se a ilusão (Gardner 1942:4).

D. perto ou ao longe, os contornos do Rio de Janeiro sempre despertaram a imaginação de viajantes, que os descreveram e retrataram com muita freqüência. Entre o período colonial e meados do Oitocentos, a cidade e a natureza se mesclaram na paisagem: ora a cidadela predominava; ora dominavam o cenário as florestas, as rochas e as águas salgadas da baía. Mr. George Gardner narrou a experiência de vêla ao longe, a bordo do navio, quando se encantou com a harmonia entre o casario e a vegetação, entre criação divina e obra humana, formando "cenário sem rival na face da terra". De perto, infelizmente, a cidade celestial tornava-se uma quimera. Com ruas estreitas e sórdidas, o Rio escravista feria a sensibilidade romântica e colonialista. As impressões sobre a urbe, porém, não se resumem à dicotomia celestial e infernal. Há uma infinidade de vistas, prospectos e paisagens que nos permitem conhecer um pouco do Rio Antigo.

As primeiras vistas se destacam pela desinformação, pela visita apressada de corsários, proibidos de pisar em solo colonial lusitano. Nesses testemunhos, o Rio resumia-se a uma pequena cidadela ao longe, onde se destacavam alguns prédios, fortificações e relevo. A partir da segunda metade XVIII, época de intenso crescimento da cidade, descrições e imagens retrataram com mais detalhes os recantos da cidade. O predomínio das vistas do mar para terra, em vôo de pássaro, arrefeceuse, originando tomadas diversas do núcleo urbano e seus arredores. Com a abertura dos portos, a cidade era vista de dentro para fora, e o cotidiano dos moradores paulatinamente retratado por olhos curiosos e intrigados pelo exotismo. A natureza, por vezes, recebeu contornos paradisíacos, e os arredores tornaram-se lugares para representar o sublime e o pitoresco, bem ao gosto romântico oitocentista. Enfim, as perspectivas de longe e perto, ou fora e dentro, servem como pretexto para este breve ensaio sobre os registros da cidade maravilhosa. 
Para passear pelo Rio de Janeiro por meio de textos e imagens, recorrerei a uns poucos, mas diversificados, testemunhos: corsários, viajantes, naturalistas, negociantes e artistas, quase todos provenientes de plagas muito além de Portugal. A escolha parte do princípio que as representações da cidade se alteraram com a evolução urbana. A consolidação da conquista lusa sobre o território, as transformações culturais e artísticas também servem como subsídios para entender os suportes da representação. Afinal, a paisagem é uma representação da representação. Longe de ser uma reprodução fiel e naturalista da natureza, a paisagem é uma criação cultural que inicialmente elege e unifica objetos isolados e os agrupa numa paisagem. A representação gráfica é a segunda etapa do processo de produção das paisagens (Mitchell 1994: 14) ${ }^{1}$.

Somente em raros momentos, portugueses e brasileiros tiveram a preocupação de descrever ou tornar visível o olhar sobre a cidade. As vistas, prospectos, panoramas e paisagens provêm, em grande parte, de artistas e viajantes estrangeiros; seja no período colonial, seja depois da emancipação política das terras brasílicas. As imagens da cidade produzidas por "estrangeiros", certamente, promoveram a construção singular de uma identidade, ou melhor, de uma auto-imagem forjada de fora para dentro. Mais tarde, os mesmos clichês seriam reproduzidos em cartão postal, na televisão e no cinema, sendo ainda responsáveis pela difusão da imagem do Brasil no exterior. No processo de construção de imagem, o Rio tornou-se símbolo do Brasil, tema fascinante e pouco estudado na historiografia. Este breve ensaio pretende, enfim, fornecer subsídios para estudos mais alentados.

\section{De fora, vistas e prospectos}

Desde os primeiros navegadores, ainda no século XVI, a baía da Guanabara é tema indispensável nos relatos de viagem pelo Atlântico sul. Os mananciais de água potável e os frutos da terra, além das belezas naturais, estavam entre as maravilhas

\footnotetext{
1 "Landscape painting is best understood, then, not as the uniquely central medium that gives us acess to ways of seeing landscape, but as a representation of something that is already a representation in its own right". (Idem: 14). Sobre questões teóricas da paisagem ver: (Kemal \& Gaskell 1995).
} 
encontradas nessas paragens. Marinheiros e viajantes, depois de uma longa travessia, curavam suas doenças e o cansaço da longa jornada alimentando-se de iguarias oferecidas pelos índios. André Thevet relatou a recepção dos tamoios quando da sua chegada na Guanabara. Demonstrando júbilo, os anciãos dirigiam saudações aos franceses e ofertaram-lhes víveres de diversas espécies: farinha de mandioca, raízes grandes e pequenas, todas de ótimo sabor (Thevet 1978: 93). Oliver van Noort e Richard Flecknoe narraram também os recursos naturais disponíveis na baía. O último esteve em terra e descreveu em detalhes as árvores frutíferas, animais e aves do ecossistema guanabarino (Taunay 1944: passim). Para além da importância dos suprimentos, o tema mais recorrente na literatura de viagem era a segurança. Depois da França Antártica, a cidade ergueu-se protegida por fortificações que, de um lado ao outro, guarneciam-na contra invasores.

As primeiras gravuras da baía são cenas de guerra, retratando confrontos entre franceses e portugueses. Ilustrando o relato de André Thevet, essas imagens destacam a participação indígena e o fogo cruzado entre as embarcações inimigas (Thevet 1575: v.II, 908v). Não há ainda autonomia do espaço enquanto tema iconográfico. Em primeiro plano está a guerra e não a incipiente fortificação francesa. De 1599, a gravura encontrada no relato de Oliver van Noort mostra a baía e seus contornos, destacando o relevo, as fortalezas e o casario. Pela primeira vez, vê-se a representação do Pão de Açúcar, que se encontra muito mais próximo do mar aberto do que a fortaleza de Santa Cruz. No plano posterior e em frente da mencionada fortaleza, erguemse as construções da urbe que estão dispostas em uma reta, como muralha (Noort 1610: 43). A imagem, portanto, demonstra o confuso conhecimento geográfico dos primeiros navegadores. A expedição de Noort não teve tempo de observar o complexo traçado da baía e da cidade. Os elementos disponíveis na imagem, por certo, viabilizariam aos holandeses melhores chances de um futuro ataque certeiro. Nicolas van Geelkerken (c.1623) também reproduziu a entrada da baía com as mesmas finalidades (Reys-boeck.., 1624). Na ilustração, os fortes estão melhor posicionados: no primeiro plano está a fortaleza de Santa Cruz, depois o Pão de Açúcar e as fortalezas de São João, São Tiago e Villegaignon. O casario parece disposto somente na parte 
baixa, não havendo, portanto, evidências nítidas do Morro do Castelo e das construções mais antigas da cidade. Os prédios religiosos estão destacados: vale mencionar a igreja de Santa Catalina (Candelária), mosteiros dos Franciscanos e Beneditinos. Nota-se ainda um significativo avanço do conhecimento que os europeus dispunham da baía, mesmo depois de 1605, quando foram proibidas entrada e permanência de estrangeiros no Brasil.

"St. Sebastian, Ville Episcopale du Brésil" é o nome da primeira vista panorâmica da cidade tomada do ancoradouro, concebida pelo matemático e "engenheiro voluntário" François Froger (Froger, 1696) 2. Estão aí dispostos os principais edifícios religiosos e administrativos. Ao contrário das imagens holandesas, não há valorização do sistema defensivo. Do lado esquerdo, encontram-se, sobre o Morro do Castelo, a Sé Velha e o Colégio da Companhia de Jesus; do lado direito, o mosteiro de São Bento. Somente o forte de São Tiago está representado, enquanto a entrada da baía e suas principais defesas estão excluídas da ilustração. Esta é a primeira vista dedicada ao aspecto arquitetônico, compondo prédios em detalhes e com mais exatidão. Na parte baixa, além de igrejas e gruas para desembarque de mercadorias, há vários sobrados de dois andares e um de três andares.

Nos anos vindouros, quando as invasões francesas atormentaram os moradores da cidade, as vistas desapareceram. Somente na segunda metade do setecentos, houve novamente a preocupação de reproduzir a cidade como "dá-se à vista", retratando com fidelidade a experiência do observador que do mar via o casario e as montanhas. Essa perspectiva foi substituída pelos vários planos e plantas da cidade, que não se preocupavam com a integração entre casario e natureza, em uma síntese mimética. Nesta fase, os planos franceses reproduzem a invasão de Duguay Trouin, em 1711, enquanto os portugueses empenhavam-se em projetos de fortificação da cidade. Somente em 1744, a cidade seria novamente reproduzida com sua complexa arquitetura,

\footnotetext{
${ }^{2}$ Segundo Nestor Goulart Reis a vista data de 1696 (Reis, 2000: 361); para Gilberto Ferrez era de 1695 (Ferrez 2000:44,I).
} 
natureza e relevo, como na vista composta por François Froger. Em meio século, a cidade cresceu rapidamente, impulsionada pelo ouro das Minas Gerais.

O desenvolvimento urbano e o controle estrangeiro dos pormenores da cidade estão evidentes na vista composta por François Moyen e James Forbes. Em 1744, quando o perigo francês ainda rondava a urbe, Moyen pintou no primeiro plano a ilha das Cobras, um pequeno barco com remadores e timoneiro. A cena possui uma perspectiva singular, pois ao fundo está o mar aberto, a fortaleza de Santa Cruz, o Pão de Açúcar, enquanto a cidade localiza-se do lado direito. O inglês James Forbes esteve durante três meses na cidade, compondo um breve relato e uma vista, datada de 1765. Forbes não tinha os portugueses em boa consideração, pois os denominou de degenerados, diferentes dos antigos que descobriram as rotas para o Oriente. $\mathrm{O}$ orgulho, a pobreza, a indolência e a superstição eram suas características principais. Elogiou, porém, o esplendor das igrejas e das cerimônias. Os prédios religiosos foram representados na vista tomada do mar para o Morro do Castelo, demonstrando enorme conhecimento sobre a geografia da cidade (Ferrez 2000: 36-37, II).

Essas vistas, porém, não se comparam com o prospecto do italiano Miguel Angelo Blasco, que representa o conjunto urbano desde o mosteiro de São Bento ao Pão de Açúcar, em c.1762. Comparar essa imagem com a vista de Froger de 1695, nos permite avaliar os enormes avanços arquitetônicos e urbanísticos. O prospecto ainda retrata a cidade do mar para terra, do ancoradouro para os prédios e a serra da Carioca. No plano principal, encontram-se o mosteiro de São Bento, a ilha das Cobras e dezenas de embarcações; ao fundo, o Pão de Açúcar e o Morro do Castelo (Ferrez 1957). Encomendado pelo conde de Bobadela, governador do Rio de Janeiro entre 1733 e 1763, o prospecto identifica com muitos detalhes os prédios, mas sobretudo os armazéns e lugares de embarque e desembarque dos navios. É ainda possível visualizar o fluxo de pequenas canoas e vários remadores que devem conduzir mercadorias para a terra firme. Para além da morfologia urbana, o artista procurou retratar o comércio e a intensa circulação no porto e nas águas da baía.

Entre a serra da Carioca e o mar, mostra-se um emaranhado de telhados, torres e janelas, criando a ilusão de uma cidade densamente povoada. No prospecto enco- 
mendado por Vilhena, datado de 1775, esse recurso pictórico não foi empregado. Os prédios se dispõem um a um frente às águas da baía, com se houvesse edificações apenas na orla. Os sobrados de dois ou três andares possuem forma padronizada, mais abstratos do que os concebidos por Blasco. Ele serve, portanto, como um mapa da cidade, localizando de forma esquemática os principais prédios religiosos e administrativos. Na parte posterior, os morros se distanciam da precisão do prospecto anterior. $\mathrm{O}$ autor concebeu as elevações também de forma conceitual, não enfatizando as particularidades do relevo. Em primeiro plano, estão os armazéns no ancoradouro, além de uns poucos barcos, demonstrando que o comércio não era a principal atividade a ser representada. Enfim, os prospectos se destacam pelos pormenores da urbe, retratados por artistas que vivenciaram seus contornos (Ferrez 2000: 33-35). No final do setecentos, pertenciam ao passado os desenhos apressados e tomados ao longe, contendo deformações do relevo e do perfil da cidade.

No último quartel do setecentos, vistas, prospectos e panoramas deixaram de retratar a cidade em toda extensão. Certamente, o crescimento da urbe, o gosto por paisagens sublimes e pitorescas provocaram o aparecimento de imagens fragmentadas do Rio de Janeiro. Elas não mais se destinavam a mapear prédios, fortalezas e logradouros da cidade colonial. Antes se detinham em determinados lugarejos, recantos, e retratam a interação entre a urbe, civitas e a natureza. Paulatinamente a iconografia da cidade tornou-se habitada por homens comuns: soldados, trabalhadores, violeiros e escravos. O cotidiano citadino, inicialmente, foi retratado por Leandro Joaquim que demonstrou enorme sensibilidade e provocou uma importante ruptura com o sistema de representação barroco. Desde o início da colonização, as artes plásticas no Brasil dedicaram-se, sobretudo, aos retratos, as vidas de santos e passagens bíblicas, concebidas para decorar igrejas e instituições civis. Datados entre 1780-90, os painéis ovais de Leandro Joaquim não somente retratam de forma secularizada a vida urbana, mas destacam o predomínio humano sobre o mundo natural: a rede de pesca próxima à igreja da Glória; a pesca 
da baleia nas águas da baía; carregador de capim; cavalo de carga, carros de boi e os bois soltos na lagoa do Boqueirão ${ }^{3}$.

Além de representar a natureza, Joaquim ainda pintou prédios, o aqueduto da Carioca, a igreja da Glória, igreja da Lapa e o largo do Carmo, sem esquecer do movimento do porto e da romaria marítima. O rompimento com motivos barrocos aconteceu no período posterior às reformas pombalinas e ao intenso processo de secularização do conhecimento ocorrido no Rio de Janeiro, no tempo dos vice-reis Marquês do Lavradio (1770-1779) e Luís de Vasconcelos e Sousa (1779-1790). Visitando o Rio em 1792, Sir George Staunton viu que no jardim público havia dois bonitos pavilhões decorados com vistas da cidade e da pesca da baleia. Ornavam ainda o teto peixes coloridos e plumas de pássaros do Brasil, demonstrando um nítido pendor das autoridades locais para a História Natural (Stauton 1798:163-4). O incentivo à produção científica, por certo, inspirou Leandro Joaquim a conceber paisagens/crônicas que valorizavam tanto a morfologia urbana quanto o cotidiano de seus habitantes.

Os painéis elípticos ainda retratam a urbe do mar para terra como nas primeiras imagens da cidade. Porém, não mais exerciam a função de guiar capitães e marinheiros de primeira viagem. O utilitarismo das vistas seiscentistas foi aos poucos substituído pelo gosto romântico, pelo sublime, pelas paisagens tropicais que imortalizaram a cidade. No período colonial, enfim, os artistas retrataram as fachadas, as fortalezas, o porto e o relevo em torno da cidade. Não se preocuparam em retratar seus habitantes, tornando a urbe desabitada e vazia. Somente com Leandro Joaquim, apesar de não ser considerado um romântico, os tipos humanos se inseriam nas vistas e prospectos.

No entanto, o cotidiano do Rio de Janeiro não deixou de intrigar inúmeros viajantes. Desde o século XVII, as festas religiosas, a economia escravista e os arredores

\footnotetext{
${ }^{3}$ Os painéis são os seguintes: "Cena marítima"; "Revista Militar no largo da Carioca", "Romaria marítima diante do Hospital dos Lázaros", "A pesca da baleia na baía do Rio de Janeiro", "Vista da praia, morro e igreja da Glória", "Vista da lagoa do Boqueirão, aqueduto da carioca e igrejas da Lapa e da Carioca", obras do Museu Histórico Nacional - RJ. Sobre os painéis ver: (Ferrez 2000:104107) e (Santos 1994).
} 
foram registrados pelos visitantes. Percebe-se então um descompasso entre texto e imagem ainda inexplorado pela historiografia: se os costumes eram observados e descritos, por que não desenhados e pintados? O interior da cidade, suas ruas e praças, os arredores e o cotidiano dos moradores tornaram-se tema dos principais registros pictóricos somente no século XIX. Em parte, essa tendência se explicaria pelo gosto romântico pela cultura popular e pelas paisagens pitorescas. Para além da questão de estilo, a iconografia colonial exercia funções distintas quando comparada às imagens românticas. A primeira atuava, sobretudo, como mapa. Além de demarcar um território, artistas e viajantes oitocentistas pretendiam registrar o impacto da paisagem sobre a sensibilidade romântica. Mas a resposta a essa indagação requer um estudo mais detido sobre a arte técnica portuguesa do período entre as reformas pombalinas e a invasão francesa em Portugal. Ao longo do período colonial, vários riscadores militares portugueses registraram os tipos humanos do Brasil, mas sem inseri-los na civitas, como era recorrente na América espanhola (Kagan 2000:1-18).

\section{De dentro, paisagens}

Em 1792, o interior da cidade foi retratado na gravura de William Alexander, que compunha a comitiva do novo embaixador inglês para a China. $\mathrm{O}$ artista compôs uma imagem rica em detalhes arquitetônicos e sociais. Cercado por montanha e vegetação tropical, o aqueduto serve de cenário para atores citadinos: monges franciscanos lendo entre arbustos, escravos carregando liteira, homem conduzindo um cavalo e carroça, transportadores de barris e vários transeuntes em frente a um ambiente urbano com construções homogêneas (Alexander 1808-1814: XIV). Ao contrário da iconografia colonial, o Rio foi retratado da cidade para o mar, de dentro para fora. Como nos painéis de Leandro Joaquim, a cena retrata o cotidiano, o casario, a vegetação e o relevo, sem recorrer aos marcantes contrastes entre mar e terra. $\mathrm{O}$ meio aquático, tema recorrente da paisagem carioca, não foi explorado na gravura, nem mesmo a lagoa do Boqueirão que à época estava, por certo, aterrada (Ferrez 2000: 104).

Interessante comparar "A vista da lagoa do Boqueirão" de Leandro Joaquim com esta imagem. Se a primeira retrata o espaço entre o mar e o aqueduto da Carioca, 
a gravura de Alexander reproduziu o intervalo entre as montanhas e o aqueduto. $\mathrm{Na}$ última, as igrejas da Lapa e Santa Teresa são vistas pela parte posterior. O contraste é esclarecedor, pois tornam-se evidentes os traços do luso-brasileiro e do inglês, sobretudo quando comparamos a arquitetura das igrejas. Em Joaquim, elas possuem formas barrocas, em Alexander góticas, com torres altas e pontiagudas. Os tipos humanos em Leandro Joaquim lembram as figurinhas de Carlos Julião e Guillobel, retratos carregados de insígnias sociais e culturais (Cunha 1960; Sela 2001). Os personagens do artista inglês são mais pobres em detalhes dessa natureza, como era de se esperar de um pintor estrangeiro e que passou rapidamente pela cidade.

Depois de 1808, com a abertura dos portos e a chegada da corte, o Rio de Janeiro cresceria com maior velocidade e seria visitado por inúmeros viajantes e artistas que reproduziram seus recantos. As missões francesa e austríaca registraram-na tanto do mar para a terra, das montanhas para o mar, explorando a maravilhosa combinação de água, montanhas, florestas e cidade. Os panoramas e vistas, do ancoradouro ou em vôo de pássaro, continuaram a retratar a urbe. Porém, os novos elementos da morfologia urbana e da geografia estão presentes nas tomadas de dentro para fora, como na gravura de William Alexander. Com liberdade de permanecer na cidade e percorrer seus arredores, os artistas multiplicaram os registros. Explorando os interiores, ora retrataram a composição formada pelos elementos térreos e aquáticos; ora minimizaram as construções urbanas, procurando destacar o predomínio da natureza sobre a paisagem; ora inseriram no meio elementos sociais, sobretudo os negros. As encenações da cidade e da natureza revelam um pouco da mentalidade urbana européia, sobretudo britânica (Martins 2001), em busca do sublime e do pitoresco, mas também fornecem preciosos subsídios sobre a civitas.

Em meio ao maciço da Tijuca, John Luccock observava os escravos desmatando um lote para construir uma casa. A queda de árvores enormes descortinou um panorama completo da cidade de São Sebastião. O efeito da beleza indescritível irrompeu inesperadamente sobre eles, deixando pasmos de admiração os próprios escravos. O silêncio e o clamor expressos por nativos de três partes diferentes do mundo eram demonstrações do encantamento pela paisagem (Luccock 1820: 300). Para o inglês, 
os efeitos da natureza sobre a sensibilidade humana estavam acima das diferenças entre os povos. O fascínio pela paisagem era, enfim, universal. Na virada para o século XIX, a pintura de paisagem tornou-se voga no meio artístico europeu, notadamente entre os britânicos. Para Dawn Ades, há dois fatores para explicar esse fenômeno: "o surgimento da nação-estado e a procura por uma identidade cultural e a mudança das atitudes para com a natureza e a história natural (Ades 1999: 14)"”4. Produzidas por estrangeiros, as paisagens do Rio de Janeiro não promoviam, em princípio, o Estado nação, nem pretendiam, em princípio, forjar a identidade brasileira. Muitos artistas estavam a serviço da investigação científica, seguindo as instruções do mestre Humboldt. Em meio a uma natureza selvagem e singular, os viajantes-artistas buscavam o avanço da História Natural e encantavam-se pelo pitoresco e pelo sublime.

Teorizando sobre o pitoresco, o reverendo William Gilpin destacou as expressões artísticas que recorriam ao selvagem, rústico e inculto (Gilpin 1982:14-35 e 42). A beleza pitoresca valorizava os contrastes de cores, formas e texturas presentes na natureza. Sintetizava uma variedade de partes compostas por objetos rudes, como montanhas, árvores e águas. Para Gilpin, o artista não devia, porém, anatomizar a matéria, mas observar e compor uma paisagem que nem sempre se confundia com a realidade, recorrendo a uma "imaginação organizadora" - imaginative organization (Bermingham 1994: 86). O sublime, por sua vez, era o triunfo da natureza sobre o homem, que diante de sua beleza perdia a razão e o controle, como no episódio descrito por Luccock. O sublime origina o assombro, "que consiste no estado de alma no qual todos os seus movimentos são sustados por certo grau de horror", provocando admiração, a reverência e o respeito (Burke 1993: 65). O Rio de Janeiro visto de dentro, da terra para o mar, estava repleto de motivos para paisagens pitorescas e sublimes.

Na melhor tradição do sublime, Nicolas Taunay retratou a Cascatinha da Tijuca de uma "perspectiva baixa", do plano inferior para superior, tornando-a monumental.

\footnotetext{
${ }^{4}$ Sobre a relação entre paisagem, nação e identidade ver também: (Prado 1999: 179-216; Mitchell 1994).
} 
Destacou ainda o contraste de cores da vegetação, rochas, montanhas e as águas. $\mathrm{O}$ céu furta-cor, entre o branco, azul, cinza e vermelho, se mistura entre os picos e a vegetação, espalhando suas cores pela parte superior do quadro. No plano inferior ainda encontram-se o pintor, o assistente negro, cachorro e cavalete, próximos a uma tropa de mulas. Recorrendo ao mesmo tema e perspectiva, o pintor brasileiro Manuel Araújo Porto-Alegre também retratou a cascata. As águas descem em meio às rochas e uma natureza variada e contrastante: árvores, trepadeiras, flores e aves coloridas. Os humanos, seres insignificantes e diminutos, estão na parte escura da tela. De cartolas e rifles, parecem fazer anotações e tomar medidas por meio de instrumentos ${ }^{5}$. São certamente naturalistas na faina diária. Essa paisagem era singular, razão para inúmeros outros artistas registrá-la como fenômeno sublime, contrastando a grandiosidade da natureza e a fragilidade humana.

A preocupação em destacar a grandiosidade da natureza frente às obras humanas está presente na aquarela do comerciante e artista inglês George Lothian Hall. Em "Montanhas do Rio de Janeiro vistas de Niterói" (1858), o pintor ampliou a magnitude das montanhas e tornou quase invisíveis as construções da cidade. Como pequenos pontos brancos, quase desaparecem frente ao relevo composto em tom lilás. Esta tonalidade colore o mar e a cadeia de montanhas em torno da baía, enquanto, em Niterói, a vegetação e solo variam entre preto e ocre. O francês Joseph Alfred Martinet compôs, em 1849, três panoramas do Rio de Janeiro e seus arredores. A partir do Corcovado, o pintor pode visualizar as águas, contornos da baía, montanhas e fazendo desaparecer a cidade. A presença humana somente existe no primeiro plano, onde senhores e senhoras, elegantemente vestidos, se deliciam com o sublime ${ }^{6}$.

Enfim, como escreveu Gilpin, a paisagem nem sempre se confunde com a realidade observada. A beleza pitoresca pressupõe a valorização dos contrastes, a in-

\footnotetext{
${ }^{5}$ Manuel Araújo Porto Alegre. Grande Cascata da Tijuca, 1833. Fundação Rank Packard.; Nicolas Antoine Taunay. Cascatinha da Tijuca. S.d. Solar da Marquesa de Santos - Museu do Primeiro Reinado/FUNART. ${ }^{6}$ George Lothian Hall. O Rio de Janeiro visto de Niterói, 1858. Coleção Sérgio Sahione Fadel.; Joseph Alfred Martinet. Panorama do Rio de Janeiro do Corcovado, 1849. Coleção Museu Castro Maia.
} 
tervenção do artista para transformar a natureza em paisagem. Recurso semelhante empregou Benjamin Mary na aquarela de 1836. Em "Rio de Janeiro - Vue de la Gloria" da coleção Ferrez, o artista pintou os Arcos da Lapa como ruínas em meio a uma vegetação densa e variada. Aí a obra humana foi suplantada pela natureza. Do conjunto arquitetônico e casario, Mary somente destacou a igreja da Glória. A iconografia do Rio de Janeiro possui, porém, excelentes exemplos de pintores dedicados à paisagem urbana, fornecendo detalhes da morfologia.

A paisagem é uma forma de estruturar o mundo, que se origina tanto na pintura como na escrita. Para entender a construção da paisagem torna-se necessário explorar suas representações escritas - imagens e significados (Daniel \& Cosgrove 1992:1). $\mathrm{Na}$ literatura de viagem oitocentista, as descrições da paisagem são recorrentes. Assim como Luccock, em 15 de dezembro de 1821, Maria Graham escreveu em seu diário:"Nada do que vi até agora é comparável em beleza à baía. Nápoles, o Firth of Forth, o porto de Bombaim e Trincomalee, cada um dos quais julgava perfeito em seu gênero de beleza, todos lhe devem render preito porque esta baía excede cada uma das outras em seus vários aspectos. Altas montanhas, rochedos como colunas superpostas, florestas luxuriantes, ilhas de flores brilhantes, margens de verdura, tudo misturando com construções brancas, cada pequena eminência coroada com sua igreja ou fortaleza, navios ancorados, ou em movimento, e inúmeros barcos movimentandose em um tão delicioso clima, tudo isso se reúne para tornar o Rio de Janeiro a cena mais encantadora que a imaginação pode conhecer" (Graham 1956:174-75).

Maria Graham expressou a emoção recorrente entre os artistas que retrataram o Rio na primeira metade dos oitocentos. No entanto, a paisagem escrita pela inglesa não se adequa à beleza pitoresca de William Gilpin. Ao definir o pitoresco, o último confrontava-se com William Marshall Craig, delimitando duas correntes da pintura de paisagem: a abstrata e a realista. A realista recorria a um método de composição analítica e aditiva; a abstrata apostava em uma síntese, fundindo os elementos da natureza (Bermingham 1994:77-101; Stafford 1984: 1-56). A vertente realista ou naturalista procurava, como as vistas e os prospectos, criar um mapa. Desde Claude Lorrain e Salvatore Rosa, esse estilo - "the great style" - alcançou enorme sucesso, 
rejeitando a abstração, valorizando a individualidade, variedade e o naturalismo orgânico. Nesse sentido, boa parte das paisagens cariocas segue a última vertente.

De Santa Teresa para o mar, H. Schmidt compôs um magnífico panorama que abrangia os sobrados da Lapa, Passeio Público, Ajuda, Morro do Castelo, alcançando ainda o centro da cidade e o mosteiro de São Bento ${ }^{7}$. O casario amarelo claro possui uma coloração padronizada, com um ou dois pavimentos e uns poucos com três. Curiosamente, as residências localizam-se entre o traçado retilíneo das ruas e quintais, onde há arbustos que, por vezes, se assemelham a pomares. No Morro do Castelo avistam-se, além de prédios e ladeiras, uma vegetação rasteira e pequenas árvores. O Passeio Público é delimitado por muro também amarelo, cercando uma vegetação exuberante e densa. Em meio à "floresta urbanizada", estão os dois obeliscos do mestre Valentim que servem de entrada. O mar está envolto por uma bruma amarelada, que impede uma visão mais nítida do outro lado da baía e da Serra do Mar, que permanecem no infinito e se confundem com o céu. Para além das altas montanhas, se descortina um céu azul intenso que fornece ao quadro luminosidade.

A Lapa também serviu de cenário para o francês Adolphe D'Hastrel compor uma belíssima litografia, retratando a igreja da Lapa e o convento de Santa Teresa, além de alguns sobrados ${ }^{8}$. Verificam-se aí algumas alterações da morfologia urbana: o convento está em plano mais baixo e próximo da igreja; o aqueduto, que deveria estar ao lado, desapareceu. No primeiro plano, avista-se uma rua composta de sobrados de dois pavimentos. Na parte superior há um pequeno balcão e uma janela, que não estão em correspondência com o andar térreo, onde se encontram duas janelas grandes como a superior, uma pequena e uma porta. Na parte lateral da igreja, o artista concebeu um muro em ruínas, bem ao gosto pitoresco. Como no panorama de H. Schmidt, nesse quintal há uma densa vegetação, composta de coqueiro, ba-

\footnotetext{
${ }^{7}$ H. Schmidt. Panorama da cidade feito de Santa Teresa, 1834. Coleção Maria Cecília e Paulo Fontainha Geyer.

${ }^{8}$ Adolphe D’Hastrel. Igreja da Lapa e convento de Santa Teresa perto do Passeio Público, 1841. Coleção Gilberto Ferrez.
} 
naneira e uma frondosa árvore. Em frente ao muro, estão vários negros exercendo seus ofícios. Uma mulher com dois tonéis, outra com trouxa sobre a cabeça e uma terceira com o filho nas costas. Os demais personagens parecem conversar. Todos são negros, concebidos como elementos do pitoresco devido à cor e aos hábitos.

Se os retratos da cidade destacam contraste pitoresco entre cores e formas, os relatos de viajantes nem sempre destacam a beleza. Os Agassiz impressionaram-se com ruas estreitas e cortadas por valas, onde se acumulavam imundícies de toda espécie. Na cidade reinava negligência e incúria, descalabro geral, resultante da umidade extrema promovida pelo clima. Os feitos nefastos da natureza, porém, se agudizam com a indolência geral dos transeuntes. Mas os viajantes e pintores se rendiam ao efeito pitoresco, fazendo desaparecer, ao menos nas paisagens, os defeitos e a desordem urbana. "Bem sabem que fascinação e encanto eles mesmos sentiram, a despeito da sujeira e da falta das coisas julgadas as mais necessárias" (Agassiz 1975: 46). Enfim o pitoresco anestesiava as críticas e as exigências de viajantes acostumados coma urbanidade das cidades do norte ${ }^{9}$. O encantamento da paisagem e a beleza pitoresca nos permitem entender o contraste entre a conturbada vivência urbana e as maravilhosas paisagens.

Os contrastes da cidade não estavam apenas entre o pitoresco e a incúria, mas entre a "velha educada Europa" e a "selvajaria americana", ressaltada nos escritos de Spix e Martius. Os naturalistas bávaros consideravam a população negra e mulata inferior, bruta. Andava seminua por toda parte da cidade, ferindo a sensibilidade do europeu, habituado a "costumes delicados e as fórmulas obsequiosas da sua pátria". $\mathrm{O}$ Rio de Janeiro era o encontro entre mundos opostos, reunindo a tradição européia e a escravidão: "Língua, costumes, arquitetura e afluxo dos produtos da indústria de todos as partes do mundo dão à praça do Rio de Janeiro aspecto europeu. O que, entretanto, logo lembra ao viajante que ele se acha num estranho continente do mundo, é sobretudo

\footnotetext{
${ }^{9}$ Vale mencionar a existência de vários sentidos para "pitoresco", sobre o assunto ver: (Conan 1982: 139-148; Bermingham 1986:63-73).
} 
a turba variegada de negros e mulatos, a classe operária com que ele topa por toda parte, assim que põe o pé em terra" (Spix e Martius 1983: I, 48).

Nem por isso os negros receberam a pecha de bárbaros na paisagem urbana do Rio de Janeiro. Em "Largo da Glória”, Henry Chamberlain construiu um ambiente urbano para mostrar vários tipos humanos presentes na cidade, muitos deles escravos de ganho (Chamberlain 1943). Mulheres e homens negros, livres ou forros, carregam sobre a cabeça as mais variadas mercadorias, figurinhas certamente copiadas do engenheiro militar português Joaquim Cândido Guillobel. Os negros na paisagem estão comumente exercendo seus ofícios, carregando água, vendendo, pescando, conduzindo o gado e carroças, plenamente inseridos no mundo do trabalho. Podem ainda desfrutar do ócio, do descanso, como na vista da igreja da Glória de Joseph Tully. Na aquarela, dois meninos negros, vendedores de frutas, encontram-se no adro da igreja, vislumbrando o panorama da baía. Os negros ainda se destacam na aquarela de Auguste Earle e na gravura de Richard Bates que inserem os negros na paisagem como trabalhadores, sem explicitar os signos da escravidão ${ }^{10}$. Essas imagens, porém, não possuem elementos anti-escravistas, nem mesmo promovem a detração dos negros como nos escritos de Spix, Martius e os Agassiz. Se, como destaca Ann Bermingham, as paisagens expressam relações de poder, a representação da cidade e do negro, em particular, permite esboçar um tema de pesquisa que, a princípio, parece muito promissor.

Os registros da paisagem destacam-se pela harmonia entre a cidade e a natureza, entre os habitantes livres e escravos. No diário, Maria Graham escreveu que a beleza da cidade estava na união, na síntese, entre florestas, rochedos, águas e o casario, que juntos proporcionavam a "cena mais encantadora que a imaginação pode conhecer". A mencionada síntese é encontrada, por certo, no imenso material iconográfico referente à cidade. Para além da interação com a natureza, as paisagens também retratam os homens, a diversidade social da cidade escravista. Comandando

\footnotetext{
${ }^{10}$ Joseph Tully. Vista da igreja da Glória, 1822. Museu Imperial; Augusto Earle. Vista da planície de Botafogo", 1832. Coleção Beatriz e Mário Pimenta Camargo; Richard Bates, "Vista de parte do aqueduto da Carioca e da rua de Mata-Cavalos, c.1835-1846. Coleção Gilberto Ferrez
} 
ou obedecendo, negros, mulatos e brancos exercem suas funções sem ameaçar a ordem. Livres ou escravos, garantiu Graham, os negros "aparecem alegres e felizes no trabalho" (Graham1956:188). Os personagens negros inseridos no mundo do trabalho expressam, igualmente, a harmonia da "encantadora paisagem", representação imune aos rumores provenientes da rebelião escrava do Haiti.

Se nas imagens não há dissonâncias, nas narrativas de viagens encontram-se, para além do encantamento, registros de uma cidade miserável, reino da incúria, onde os negros assediam os apavorados viajantes. O contraste, portanto, vislumbra o caráter ideológico das paisagens. Por dedicar-se à representação da natureza - natureza que se confunde com ciência e verdade - a paisagem/representação tende, por vezes, a naturalizar as relações sociais. Quanto mais realista é a pintura mais persuasiva, "naturalizadora" e ilusionista ${ }^{11}$. Nesse sentido, na paisagem, a harmonia da natureza resvala para a sociedade, como no trecho a seguir.

Em 24 de janeiro, ao partir da Guanabara, Maria Graham volta a registrar mais uma preciosa observação no diário: “... se um país montanhoso e pitoresco tem realmente, mais do que outros, o poder de atrair seus habitantes, os fluminenses deveriam ser tão grandes patriotas quanto quaisquer outros no mundo" (Graham 1956: 212). O comentário parte do princípio que a natureza forja também a identidade, o sentimento pátrio. $\mathrm{O}$ culto à natureza, por certo, torna-se elemento aglutinador da sociedade. Essa construção também realizava-se junto a um público letrado e consumidor de pintura. Como a pintura histórica, a paisagem atuava como elemento construtor da identidade nacional. A literatura romântica oitocentista possui essa exata medida, compondo natureza rica e variada, quase paradisíaca. O sentimento pátrio mencionado por Graham seria, mais tarde, explorado e incorporado aos símbolos nacionais. A harmonia entre a natureza e os homens era, por certo, emblema da Nação.

A inserção de artistas ao projeto estatal é tema pouco explorado. No entanto, dificilmente é possível vincular esses pintores, ao menos boa parte deles, à

\footnotetext{
${ }^{11}$ Para Ann Bermingham (1984: 77-101) há uma interessante correlação entre ideologias políticas e os estilos de paisagem. Sobre o caráter ilusionista da pintura: (Gombrich 1986: 159-209).
} 
construção da identidade nacional. Somente no Segundo Império houve um programa estatal de incentivo à pintura. Para impulsionar o patriotismo, Araújo Porto Alegre, diretor da Academia de Belas Artes, incentivou estudos da natureza brasileira, em substituição ao exercício de cópia de mestres europeus. A pintura de paisagem seria, por conseguinte, um veículo de divulgação das particularidades do Brasil. Por outro lado, o governo imperial pretendia criar uma imagem de nação capaz de escamotear a realidade escravista (Meghreblian1990). Na Academia, entre 1850 e 1880, sob o fomento do Estado, se produziu e difundiu, sobretudo, a monumental pintura histórica, destinada a glorificar homens ilustres e batalhas. Nos salões, exibiam-se ainda retratos do imperador e da família real como parte de uma política de consolidação monárquica. Ao contrário da mencionada pintura de paisagem, a pintura brasileira, originada da Academia, não valorizava índios e negros, recorrendo aos brancos, à nobreza e a temas europeus para compor quadros.

Desde Leandro Joaquim, porém, o negro tornou-se recorrente na paisagem, atuando, quase sempre, como tema pitoresco que se vincula mais à voga européia e menos aos ditames das elites locais. Mais uma vez, percebe-se que a composição de vistas e paisagens cariocas se forjaram segundo uma lógica externa. As vistas procuravam mapear o território, fornecendo, por vezes, detalhes indispensáveis a intervenções bélicas. Com as paisagens, percebe-se o gosto pelo sublime e pitoresco, gosto estético europeu, que contrariava os temas da pintura produzida na Academia de Belas Artes. Mesmo assim essas imagens tornaram-se clichês do Rio de Janeiro, encontrados ainda hoje em cartões postais, no cinema e na televisão.

\section{Referências Bibliográficas}

ADES, Dawn. "Os artistas viajantes, a paisagem e representações do Brasil”. In: O Brasil Redescoberto. Rio de Janeiro, Paço Imperial/MinC IPHAN, 1999.

AGASSIZ, Luiz e AGASSIZ, E. Viagem ao Brasil, 1865-1866. (trad.) Belo Horizonte/São Paulo, Itatiaia Ed./Edusp, 1975.

ALEXANDER, William. The aqueduct in Rio de Janeiro. In: John Pinkerton. A general collection of the best and most interesting Voyages and Travels... London, 1808-1814. 
BERMINGHAM, Ann. Landscape and ideology. Berkeley, University of California Press, 1986. System, order, and abstraction In: W.J.T. Mitchell. (ed.) Landscape and power. Chicago, Chicago University Press, 1994.

BURKE, Edmundo. Uma investigação filosófica sobre a origem de nossas idéias do sublime e do belo. (trad.) Campinas, Papirus, 1993.

CHAMBERLAIN, Henry. Vistas e costumes da cidade e arredores do Rio de Janeiro em 1819-20. Rio de Janeiro, Kosmos, 1943.

CONAN, Michel. "La querelle du pittoresque”In: William Gilpin. Trois essais sur le beau pittoresque (orginal em inglês 1792). Paris, CEP Editions du Moniteur, 1982.

CUNHA, Lígia. Introdução histórica e catálogo descritivo. In: Riscos iluminados... Rio de Janeiro, Biblioteca Nacional, 1960.

DANIEL, S and Cosgrove, D. Introduction: iconography and landscape. In: The iconography of landscape. Cambridge, Cambridge University Press, 1992.

FERREZ, Gilberto. Um panorama do Rio de Janeiro de 1775. Revista do Instituto Histórico e Geográfico Brasileiro, 223, 1957.

Iconografia do Rio de Janeiro; 1530-1890. Catálogo Analítico. Rio de Janeiro, Casa Jorge Editorial, 2000.

FROGER, François. Relation d'un voyage fait en 1695, 1696 \& 1697... Paris, chez Michel Brunet, 1698.

GARDNER, George. Viagem ao Interior do Brasil (1836-1841). (trad.) São Paulo, Companhia Editora Nacional, 1942.

GILPIN, William. Trois essais sur le beau pittoresque (orginal em inglês 1792). Paris, CEP Editions du Moniteur, 1982.

GOMBRICH, E.H. Arte e ilusão. (trad.) São Paulo, Martins Fontes, 1986.

GRAHAM, Maria. Diário de uma viagem ao Brasil. (trad.) São Paulo, Companhia Editora Nacional, 1956.

KAGAN, Richard. Urban Images of Hispanic World - 1493-1793. New Haven, Yale University Press, 2000.

KEMAL, S. and GASKELL, I. (eds.) Landscape, natural beauty and the arts. Cambridge, Cambridge University. Press, 1995.

LUCCOCK, John . Notes on Rio de Janeiro and ...London, 1820.

MARTINS, Luciana de L. O Rio de Janeiro dos Viajantes. Rio de Janeiro, J. Zahar ed., 2001. 
MEGHREBLIAN, Caren Ann. Art, politics and historical perception in imperial Brasil 1854/1884. PhD thesis. Univesity of California, 1990.

MITCHELL, W.J.T. Imperial Landscape. In: Landscape and power. Edited by Mitchell. Chicago, Chicago University Press, 1994.

NOORT, Oliver van . Description du Penible Voyage... Amsterdan, 1610.

PRADO, Maria Lígia C. América Latina no Século XIX. São Paulo, Edusp/Edusc, 1999.

REIS, Nestor Goulart. Imagens de vilas e cidades do Brasil Colonial. São Paulo, Edups/ Fapesp, 2000.

Reys-boeck van het rijcke Brasilien. N.G. Ghedruckt int Jaer onses Heeren, 1624.

Sela, Eneida. Desvendando figurinhas. Dissertação de mestrado. Campinas, 2001. ex. mimeo.

SPIX, J. \& Martius, C.F.P. von. Viagem ao Brasil. (trad.) Belo Horizonte/São Paulo, Itatiaia Ed./Edusp, 1983.

STAFFORD, Barbara M. Voyage into substance; art,science, and illustrated travel account, 1760-1840. Cambridge, MIT Press, 1984.

TAUNAY, Afonso E. Visitantes do Brasil Colonial. São Paulo, Companhia Editora Nacional, 1944.

THEVET, André. As singularidades da França Antártica. (trad.) Belo Horizonte: Itatiaia/ Edusp, 1978.

. La cosmographie universelle. Paris, 1575.

SANTOS, A. Os painéis elípticos de Leandro Joaquim na pintura do Rio de Janeiro setecentista. Gávea, 11, 1994.

STAUNTON, Sir George. An authentic account of an embassy from the King of Great Britain... London, Bulmer \& Co, 1798. 